\title{
Oral Administration of Methylphenidate (Ritalin) Affects Dopamine Release Differentially Between the Prefrontal Cortex and Striatum: A Microdialysis Study in the Monkey
}

\author{
Tohru Kodama, ${ }^{1}$ Takashi Kojima, ${ }^{1}$ Yoshiko Honda, ${ }^{1}$ TTakayuki Hosokawa, ${ }^{1,2}$ ○Een-ichiro Tsutsui, ${ }^{2}$ \\ and $\odot$ Masataka Watanabe ${ }^{1}$ \\ ${ }^{1}$ Department of Physiological Psychology, Tokyo Metropolitan Institute of Medical Science, Setagaya, Tokyo 156-8506, Japan, and ${ }^{2}$ Division of Systems \\ Neuroscience, Tohoku University Graduate School of Life Sciences, Aoba-ku, Sendai 980-8577, Japan
}

\begin{abstract}
Methylphenidate (MPH; trade name Ritalin) is a widely used drug for the treatment of attention deficit hyperactivity disorder (ADHD) and is often used as a cognitive enhancer. Because MPH increases dopamine (DA) release by blocking the DA transporter in the human striatum, MPH is supposed to work on attention and cognition through a DA increase in the striatum. However, ADHD patients show impaired prefrontal cortex (PFC) function and MPH administration is associated with increased neural activity in the PFC. Although MPH is indicated to increase DA release in the rat PFC, there has been no study to examine MPH-induced DA changes in the human PFC because of technical difficulties associated with the low level of PFC DA receptors. Using the microdialysis technique, we examined the effects of oral administration of MPH on DA release in both the PFC and striatum in the monkey. We also tested the effect of MPH on cognitive task performance. As in human studies, in the striatum, both high and low doses of MPH induced consistent increases in DA release $\sim 30$ min after their administrations. In the PFC, a consistent increase in DA release was observed $1 \mathrm{~h}$ after a high dose, but not low doses, of MPH. Low doses of MPH improved cognitive task performance, but a high dose of MPH made the monkey drowsy. Therefore, low-dose MPH-induced cognitive enhancement is supported by striatum DA increase.
\end{abstract}

Key words: dopamine; methylphenidate; microdialysis; monkey; prefrontal cortex; striatum

Significance Statement

Methylphenidate (MPH) is a widely used drug for the treatment of attention deficit hyperactivity disorder and is often used as a cognitive enhancer. Although human positron emission tomography studies suggest that MPH works on attention and cognition through dopamine (DA) changes in the striatum, there has been no study to examine MPH-induced DA changes in the human prefrontal cortex (PFC). Using the microdialysis technique in monkeys, we found, for the first time, that low doses of MPH consistently increased DA release in the striatum but did not in the PFC. Cognitive enhancement effects of low doses of MPH are supposed to be supported by the striatum DA increase.

\section{Introduction}

Attention deficit hyperactivity disorder (ADHD) is a common behavioral disorder in childhood (Spencer, 2002; Biederman and Faraone, 2005). Methylphenidate (MPH; trade name Ritalin) is a

\footnotetext{
Received July 4, 2016; revised Dec. 26, 2016; accepted Jan. 21, 2017.

Author contributions: T. Kodama, K.T., and M.W. designed research; T. Kodama, T. Kojima, Y.H., and M.W. performed research; T. Kojima, Y.H., T.H., and K.T. contributed unpublished reagents/analytic tools; T. Kodama, T.H., and M.W. analyzed data; T. Kodama and M.W. wrote the paper.

This work was supported by the Ministry of Education, Culture, Sports, Science and Technology of Japan (Grantin-Aid for Scientific Research JP25280052 to T.K. and Grants JP24223004 and JP26540073 to M.W.).

The authors declare no competing financial interests.

Correspondence should be addressed to Masataka Watanabe, Department of Physiological Psychology,

Tokyo Metropolitan Institute of Medical Science, 2-1-6 Kamikitazawa, Setagaya, Tokyo 156-8506, Japan.

E-mail: watanabe-ms@igakuken.or.jp.

DOI:10.1523/JNEUROSCI.2155-16.2017

Copyright (C) 2017 the authors $\quad 0270-6474 / 17 / 372387-08 \$ 15.00 / 0$
}

widely used drug for the treatment of ADHD (Greenhill, 2001). It can also be used for the enhancement of cognitive and attention task performance in the human (Mehta et al., 2000; Linssen et al., 2012), monkey (Gamo et al., 2010; Rajala et al., 2012, 2015), and rat (Berridge et al., 2006; Spencer et al., 2012). MPH blocks the dopamine (DA) transporter and thereby elevates the extracellular DA level in the mammalian brain (Volkow et al., 2002). In human positron emission tomography (PET) studies, oral administration of MPH was shown to increase DA release in the striatum (Volkow et al., 2001; del Campo et al., 2013). Therefore, MPH administration is supposed to work on attention and cognition in ADHD patients and normal subjects through the DA increase in the striatum. However, ADHD patients show impaired prefrontal cortex (PFC) function (Castellanos and Tannock, 2002) and human imaging studies of MPH effects indicate enhanced 
efficiency of the PFC blood oxygen level-dependent response associated with improved working memory (WM) performance (Mehta et al., 2000). PFC DA is well documented to play an important role in cognitive operations both in humans and animals (Robbins and Arnsten, 2009). Although DA release has been investigated in the human striatum by PET, there are difficulties for measuring DA levels in the PFC using PET because of the low concentration of D2/D3 receptors in this area of the brain, for which endogenous released DA competes with the radiolabeled PET agent that binds to the receptor. Therefore, there has been no study to examine MPH-induced DA changes in the human PFC.

In the rat, there are data indicating that low doses of $\mathrm{MPH}$, which facilitate cognitive task performance, increase DA release substantially in the medial PFC but have a minimum impact on DA release outside of the PFC (Berridge et al., 2006). Therefore, it is not clear which area (PFC or striatum) of DA increase contributes more to the cognitive enhancement caused by MPH administration in the human.

We demonstrated previously that the microdialysis technique allows us to detect the basal DA level and its changes associated with task performance in the monkey PFC (Watanabe et al., 1997; Kodama et al., 2014). Therefore, we used the microdialysis method to examine the effects of oral administration of MPH on DA release in both the PFC and striatum in the monkey, the brain of which is much more similar to the human brain than is the rat brain. Although there have been some microdialysis studies to examine amphetamine-induced DA release in both the PFC and striatum of the monkey (Jedema et al., 2014; Narendran et al., 2014), these studies were conducted on anesthetized monkeys with intravenous injection of the drug. For the first time, we compared the effect of oral administration of $\mathrm{MPH}$ on DA release between the PFC and striatum in awake monkeys.

We also tested the effects of oral administration of $\mathrm{MPH}$ on cognitive task performance (delayed response, go/no-go, and self-control tasks) in the monkey to confirm previous studies indicating cognitive enhancement induced by MPH administration in monkeys (Gamo et al., 2010; Rajala et al., 2012, 2015). Considering the importance of PFC DA in cognitive operations, especially in behavioral inhibition that is impaired in ADHD patients, we expected that there would be an increase in DA release, not only in the striatum, but also in the PFC after oral administration of MPH.

\section{Materials and Methods}

\section{Subjects and surgical preparations}

Two Japanese male monkeys (Macaca fuscata) (Monkeys M and J, weighing $5.5 \mathrm{~kg}$ and $6.5 \mathrm{~kg}$, respectively), were used for this experiment. All experiments were conducted in accordance with the National Academies Press guidelines for animal experiments and were approved by the ethics committee of our institute.

The monkeys were surgically prepared under ketamine $(10 \mathrm{mg} / \mathrm{kg}$, i.m.) and pentobarbital anesthesia (Nembutal, $25 \mathrm{mg} / \mathrm{kg}$, i.v.) under sterile conditions. First, a hollow rod ( $15 \mathrm{~mm}$ in diameter) was attached to the posterior part of the skull approximately at $\mathrm{L}$ (lateral from the midline) $=0$ and $\mathrm{A}$ (anterior from the interaural line $)=-10(\mathrm{~mm})$ in the stereotaxic coordinate system, with dental acrylic for head fixation. Antibiotics were administered for $7 \mathrm{~d}$ postoperatively.

The monkeys were then trained on two kinds of cognitive tasks, as described below, with their heads partially restrained to the frame of a monkey chair. They could move their head maximally $5 \mathrm{~cm}$ in the anterior-posterior direction. They were trained until they attained $65-70 \%$ correct performance for each task in a daily session and were not trained further so that the cognitive enhancement effect of oral MPH administration on task performance could be tested later. They were also trained to be accustomed to the resting state when they were required to sit

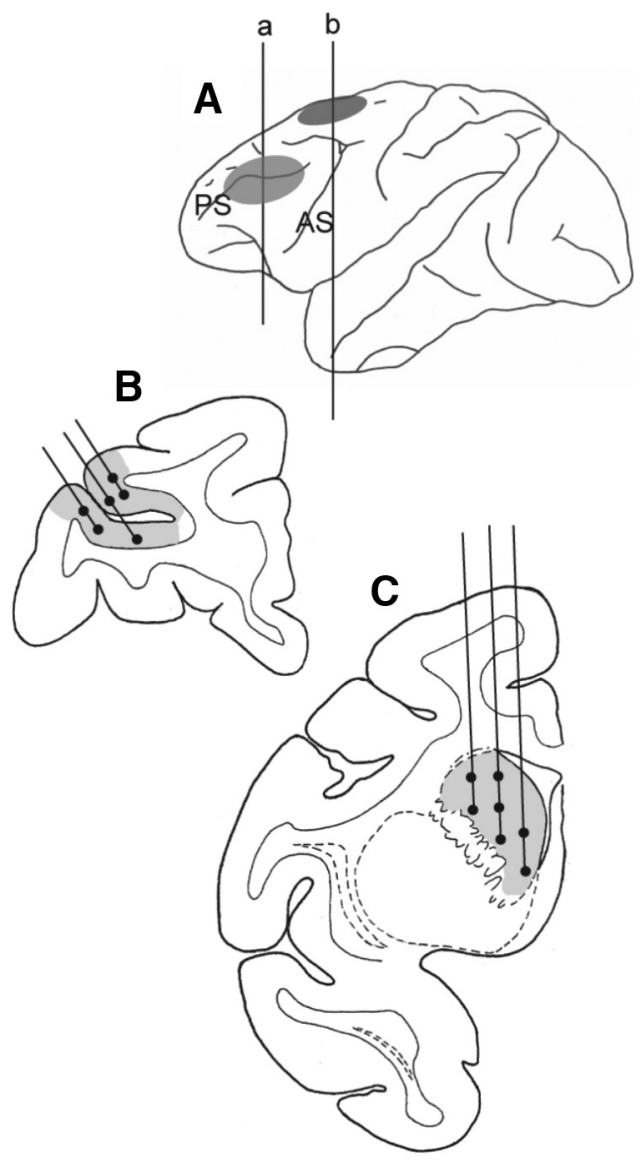

Figure 1. Schematic illustration of areas where microdialysis probes were inserted. Only areas in the left hemisphere are shown. $\boldsymbol{A}$, Shaded circle areas indicate the areas where platforms for microdialysis guide cannulae were attached and microdialysis probes were inserted. $\boldsymbol{B}$, Coronal section (at the level of line a in A, A 32 in A-P coordinate) of the prefrontal cortex indicating areas (shaded) where microdialysis sampling was conducted. $C$, Coronal section (at the level of line $b$ in A, A 20.5 in A-P coordinate) of the striatum areas (shaded) where microdialysis sampling was conducted. For $\boldsymbol{B}$ and $\boldsymbol{C}$, filled circles indicate approximate positions where the tips of microdialysis probes were located.

quietly on the monkey chair with their heads partially restrained. The duration of the resting period was gradually increased to $4 \mathrm{~h}$ a day during and after the cognitive task training over $\sim 2$ months.

We conducted the second surgery under sterile conditions. A $20 \times 20$ $\mathrm{mm}$ piece of bone above the lateral PFC (LPFC) of the right hemisphere was removed and a rectangular platform composed of acrylic resin (inner size, $20 \times 20 \mathrm{~mm}$ ) for microdialysis guide cannulae was attached to the skull just above the exposed area (the center of the platform was aimed at $\mathrm{L}=15$ and $\mathrm{A}=35$ ) using dental acrylic. Next, extracellular neuronal activity was recorded from the LPFC, mainly from the dorsal LPFC, including the depth of the principal sulcus (Fig. 1A,B), using Elgiloy electrodes to determine the target positions (where neuronal activities could be recorded) for microdialysis sampling. The recording area was determined with reference to MRIs (whole-brain coverage, $2 \mathrm{~mm}$ slice thickness; Sonata 1.5 T; Siemens). The rectangular platform was used as a microdrive (MO-95C; Narishige) receptacle for recording neuronal activities. Microdialysis sampling was then conducted from the right LPFC.

After the sampling experiments were over from the right LPFC, the third surgery was conducted to perform the sampling from the left LPFC (the center of the platform was aimed at $\mathrm{L}=-15$ and $\mathrm{A}=35$ ). Extracellular neuronal activity was recorded from the left LPFC. After the sampling experiments in this area, the fourth surgery was conducted to perform the sampling from the striatum. A $20 \times 20 \mathrm{~mm}$ piece of bone was exposed above the striatum and a rectangular platform was attached 
to the skull above the exposed area. The center of the platform was aimed at $\mathrm{L}=0$ and $\mathrm{A}=25$. Extracellular neuronal activity was recorded from the striatum, mainly from the dorsal caudate area of both the right and left hemispheres (Fig. 1 $A, C$ ).

Microdialysis study

On each day of the microdialysis experiment, each monkey was given 10 $\mathrm{ml}$ of water (indicated here as MPH $0 \mathrm{mg} / \mathrm{kg}$ ) orally or $10 \mathrm{ml}$ of a certain dose of MPH $(1,2,5$, or $10 \mathrm{mg} / \mathrm{kg})$ dissolved in water. MPH was suspended in water at $\sim 50^{\circ} \mathrm{C}$ and was administered orally at $\sim 35^{\circ} \mathrm{C}$. On each day of the experiment, the dose of MPH was determined according to a predetermined semirandom sequence with the condition that a day with an MPH dose of $10 \mathrm{mg} / \mathrm{kg}$ was not followed or preceded by a day with an MPH dose of $5 \mathrm{mg} / \mathrm{kg}$ and that the same dose did not occur on 2 consecutive days. Therefore, the following sequence of MPH doses was used: 2, 10, 0, 5, 1, 2, 5, 1, 10, and $0 \mathrm{mg} / \mathrm{kg}$. Each monkey was seated on a monkey chair with its head partially restrained. So that the animal would be partially water deprived and drink all of the fluid (water or MPH dissolved in water) before the microdialysis sampling at the start of each day's experiment, the animal was given the daily water supply $(500 \mathrm{ml})$ just after the daily experiment was over in the home cage. Monkeys could access water ad libitum during the weekend. They were given a daily ration of monkey pellets with appropriate vegetables in the home cage.

For each experimental session, 4-6 guide cannulae (type AG; Eicom; diameter: outer, $0.5 \mathrm{~mm}$; inner, $0.4 \mathrm{~mm}$ ) were fixed through the platform just above the target area. The tips of the guide cannulae were located 1 $\mathrm{mm}$ above the appropriate positions within the gray matter that had been determined by the recording of neuronal discharges. To avoid transient changes in neurotransmitters, $\sim 20 \mathrm{~h}$ before the start of the experiment, coaxial microdialysis probes (Type A-I; Eicom) with a semipermeable membrane of $2 \mathrm{~mm}$ in length and $0.22 \mathrm{~mm}$ in diameter at their tips were inserted into the appropriate locations in the LPFC or striatum through the implanted guide cannulae. For each experimental day, after dialysis samples became stably obtained, MPH was administered orally and samples were obtained every $15 \mathrm{~min}$ for $4 \mathrm{~h}$. Microdialysis probes were perfused with artificial CSF at a flow rate of $2 \mu \mathrm{l} / \mathrm{min}$. Thirty microliters $(2$ $\mu \mathrm{l} / \mathrm{min} \times 15 \mathrm{~min}$ ) of dialysate collected at $10^{\circ} \mathrm{C}$ in polypropylene sample tubing during each task were kept under acidic conditions, $\mathrm{pH} 3.5$. The specimens were frozen immediately and stored at $-80^{\circ} \mathrm{C}$. The DA level in the perfusate was determined by a high-performance liquid chromatography and an electrochemical detection system. The detection limit was $0.5 \mathrm{fmol} / 20 \mu \mathrm{l}$ injection. The sampling experiment was performed between 9:00 and 14:00 on two consecutive days after the day of microdialysis probe insertion while the animal was sitting on the monkey chair in an awake state without task performance.

\section{Normalization of DA concentration}

The concentration of DA was measured at each sampling point at each 15 min time period. Preliminary microdialysis studies revealed that there was no change in DA release within $15 \mathrm{~min}$ after the oral administration of any dose of MPH in either the LPFC or the striatum. Therefore, the DA concentration obtained during the first $15 \mathrm{~min}$ of sampling was used as the basal level. The DA concentration at each sampling position at each time period was expressed as the percentage increase or decrease over the basal DA level at each sampling point to normalize the variations between the animals and between the different experimental days.

\section{Tasks}

After all of the sampling experiments were over, monkeys were tested on cognitive tasks after water or water-dissolved MPH administration. They had been trained on the delayed response and go/no-go tasks until attaining $65-70 \%$ correct performance before the microdialysis sampling experiment. They were newly trained on the self-control task as described below. We tested the performance of the animals after orally administrating either water (MPH $0 \mathrm{mg} / \mathrm{kg})$, or a certain dose of MPH $(1,2$, or 5 $\mathrm{mg} / \mathrm{kg}$ ). When $10 \mathrm{mg} / \mathrm{kg} \mathrm{MPH}$ was administered, animals always became drowsy and their responses were unstable. We tested the animals' task performance only twice with this dose of MPH because we found that both monkeys performed the task only sporadically and we could not obtain reliable data. On each day of the experiment, the dose of MPH was
A Trial start
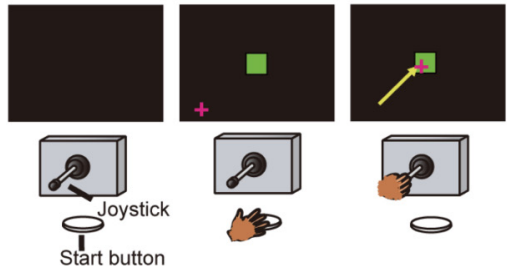

B Delayed Response task
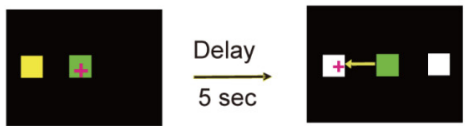

$0.5 \mathrm{sec}$

C Go/No-go task
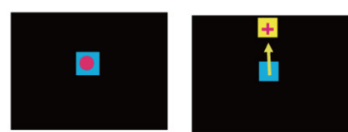

Go response
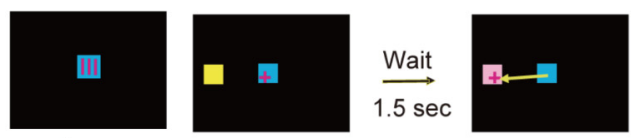

No-go response

D Self Control task

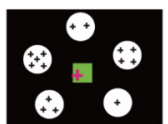

$0.5 \mathrm{sec}$

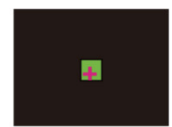

Delay $(1 \mathrm{sec})$

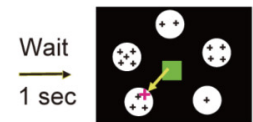

Figure 2. Task description of three kinds of cognitive tasks. $\boldsymbol{A}$, For all tasks, the monkey faced a 19-inch computer display that was located $\sim 57 \mathrm{~cm}$ from the monkey's eyes and a joystick and a start button that were vertically arranged. The animal first was required to press the start button and then was required to move the plus-mark cursor to the center square (green color) by manipulating the joystick. $\boldsymbol{B}$, Delayed response task. After the delay period was over, the animal could obtain the juice reward by moving the cursor to the white square where the yellow

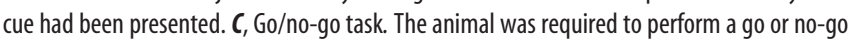
response depending on the previously presented visual cue. In go trials, the animal had to respond within $1 \mathrm{~s}$ after the appearance of the yellow target, whereas in no-go trials, the animal was required to refrain from responding for $1.5 \mathrm{~s}$ of the no-go period. $\boldsymbol{D}$, Self-control task. The animal was required to choose one of 5 circle stimuli, within which a different number of plus marks $(1,2,3,4$, or 5$)$ were included. The number of plus marks within each circle indicated both the magnitude of reward and the waiting time until reward delivery; the larger the number of plus marks within each circle, the larger the magnitude of the reward and the longer the waiting time until reward delivery.

determined according to a semirandom sequence as was used for the microdialysis studies, except that animals were not tested with a dose of $10 \mathrm{mg} / \mathrm{kg}$ after being tested twice with this dose.

For all of the tasks, the monkey faced a 19-inch computer display that was located $\sim 57 \mathrm{~cm}$ from the monkey's eyes and the joystick and start button that were vertically arranged (Fig. $2 A$ ). The animal was first required to press the start button to initiate the task. When the animal pressed the button, a green square $(10 \times 10 \mathrm{~cm})$ was presented at the center of the display and a plus-mark cursor $(5 \times 5 \mathrm{~cm})$ appeared at one of the four corners of the display simultaneously. The animal was then required to move the plus-mark cursor to the center square (green) by manipulating the joystick.

Delayed response task. The delayed response test is shown in Figure 2B. When the animal kept the cursor within the square for $0.5 \mathrm{~s}$, a yellow 
square cue $(10 \mathrm{~cm} \times 10 \mathrm{~cm})$ was presented for $0.5 \mathrm{~s}$ either on the right or left side of the display. There was then a delay period of $5 \mathrm{~s}$. When two white squares (each $10 \times 10 \mathrm{~cm}$ ) were presented on both the right and left sides of the display, the animal could obtain $0.3 \mathrm{ml}$ of juice as a reward by moving the cursor to the white square where the yellow cue had been presented.

Go/no-go task. The go/no-go task is shown in Figure $2 C$. When the animal kept the cursor within the square for $0.5 \mathrm{~s}$, a pattern cue was presented for $1 \mathrm{~s}$ within the center square that was blue in this task. There were four different cues. Two of them (circle and square) indicated a go response and the other two (stripe and inverted triangle) indicated a no-go response to the monkey. A target stimulus of a yellow square then appeared at one of the top, bottom, right, or left sides of the display. On go trials, when the animal moved the cursor to the target within $1 \mathrm{~s}$ after the appearance of the target, the $0.3 \mathrm{ml}$ of juice reward was delivered. On no-go trials, the animal was required to keep the cursor within the center square for another $1.5 \mathrm{~s}$ (no-go period). After the no-go period was over, the color of the target was changed from yellow to pink and the animal could obtain the $0.3 \mathrm{ml}$ of reward by moving the cursor to the target.

Self-control task. The self-control task is shown in Figure 2D. When the animal kept the cursor within the square for $0.5 \mathrm{~s}, 5$ circle stimuli (same size and white), within which a different number of plus marks $(1,2,3,4$, or 5) were included, were simultaneously presented on the display for $0.5 \mathrm{~s}$. Then, there was a delay period of $1 \mathrm{~s}$. When the same 5 circle stimuli were presented again, the animal was required to choose one of the 5 circles and move the cursor to the chosen circle within $1.5 \mathrm{~s}$. The number of plus marks within each circle indicated both the magnitude of the reward $(0.25,0.30,0.35,0.40$, or $0.50 \mathrm{ml})$ and the waiting time until reward delivery $(3,5,8,10$, or $12 \mathrm{~s})$; the larger the number of plus marks within each circle, the larger the magnitude of the reward and the longer the waiting time until reward delivery. Locations of these five keys with different plus marks were selected randomly in each trial so that the animal would not develop a position habit. The duration of each trial in this task was fixed at $15 \mathrm{~s}$, so when the animal chose a key with a shorter waiting time, it had to wait for a longer period until the start of the next trial. Therefore, the number of trials within a certain period was almost the same regardless of the monkey's choice. The monkey was better off choosing a circle with a larger number of plus marks to obtain a larger amount of juice reward for each trial even if it was reluctant to wait for a longer delay. Monkeys were trained to perform this task, first with 2 circles, then with 3,4 , and finally 5 circles with a circle with a larger number of plus marks associated with a longer delay and larger reward. We trained the monkey until it appeared to respond differently to keys with a different number of plus marks (it took $\sim 2$ weeks for the animal to become able to do so).

In behavioral tests with MPH administration, monkeys were allowed to start task performance $1 \mathrm{~h}$ (which is well after the time when MPH was shown to change DA release in the striatum) after MPH administration. Monkeys performed these three different kinds of tasks each for $\sim 200$ trials, with the order of the task changed every day so that the elapsed time after the MPH administration was counterbalanced among the three tasks. Monkeys were partially water deprived and obtained all of their daily fluid by performing the task. When the animal was still motivated to perform the task after completing $\sim 600$ trials of all 3 tasks in $\sim 2 \mathrm{~h}$, it was allowed to perform the last task for that experimental day until it was satiated with fluid. Monkeys could access water ad libitum in the home cage during the weekend.

\section{Statistics}

For the microdialysis study, data of both monkeys were combined and a two-way ANOVA with a repeated-measures design and a post hoc test with Ryan's method were used for statistical analyses. For the behavioral study also, data from both monkeys were combined. A one-way ANOVA was used for the data on the delayed response and go/no-go task and a two-way ANOVA was used for the data on the self-control task, both with a repeated-measures design and a post hoc test with Ryan's method. The statistically significant level was set at $p<0.05$.

\section{Results}

\section{Changes in DA release in the LPFC and striatum for the $4 \mathrm{~h}$ sampling period}

Changes in DA release for each dose of MPH administration ( 0,1 , 2, 5, and $10 \mathrm{mg} / \mathrm{kg}$ ) and for each elapsed time after MPH administration (15 min-1 h, 1-2 h, 2-3 h and 3-4 h) are illustrated in Figure 3 for the LPFC (Fig. $3 A$ ) and striatum (Fig. 3B). A two-way ANOVA of DA release was performed with the dose of $\mathrm{MPH}$ and the elapsed time after MPH administration as main factors.

In the LPFC, there were significant main effects for both factors of dose difference $\left(F_{(4,168)}=3.648, p=0.0122\right)$ and elapsed time $\left(F_{(4,168)}=8.287, p<0.001\right)$. There was also a significant interaction between the two factors $\left(F_{(16,168)}=2.334, p=\right.$ 0.0039). Multiple comparisons using Ryan's method indicated that the increases in DA release were significantly higher with the dose of MPH $10 \mathrm{mg} / \mathrm{kg}$ than with the dose of MPH $0 \mathrm{mg} / \mathrm{kg}(p<$ $0.01)$. In addition, the DA releases were significantly higher than the basal level during the elapsed time periods of $1-2 \mathrm{~h}(p<$ $0.05), 2-3 \mathrm{~h}(p<0.001)$, and 3-4 h $(p<0.001)$. Further analysis revealed that there were significant differences in DA release among different elapsed time periods when MPH $10 \mathrm{mg} / \mathrm{kg}$ was administered $(p<0.001)$. During the $1-2 \mathrm{~h}, 2-3 \mathrm{~h}$, and $3-4 \mathrm{~h}$, but not the $15 \mathrm{~min}$ to $1 \mathrm{~h}$ periods, there were significant differences in DA release depending on the MPH dose difference. Within each elapsed time period, statistically significant differences in DA release between different MPH doses are indicated in Figure $3 A$. Importantly, in each elapsed time period, significant differences in DA release depending on the MPH dose difference were observed only between the dose of $10 \mathrm{mg} / \mathrm{kg}$ and other doses and there were no significant differences in DA release between the MPH $0 \mathrm{mg} / \mathrm{kg}$ dose and the MPH 1, 2, and $5 \mathrm{mg} / \mathrm{kg}$ doses in the LPFC.

For the DA release in the striatum, there were significant main effects for both factors of dose difference $\left(F_{(4,236)}=3.374\right.$, $p=0.0149)$ and the elapsed time $\left(F_{(4,236)}=28.650, p<0.001\right)$. There was also a significant interaction between the two factors $\left(F_{(16,236)}=2.129, p=0.0080\right)$. Multiple comparisons using Ryan's method indicated that the increases in DA release were significantly higher with the dose of MPH $10 \mathrm{mg} / \mathrm{kg}$ than with the dose of MPH $0 \mathrm{mg} / \mathrm{kg}$ ( $p<0.005)$. In addition, the DA releases were significantly higher than the basal level during the elapsed time periods of $15 \mathrm{~min}$ to $1 \mathrm{~h}, 1-2 \mathrm{~h}, 2-3 \mathrm{~h}$, and 3-4 h (all $p<$ 0.001 ) and they were significantly higher during the elapsed time periods of $1-2 \mathrm{~h}, 2-3 \mathrm{~h}$, and $3-4 \mathrm{~h}$ than during the $15 \mathrm{~min}$ to $1 \mathrm{~h}$ period (all $p<0.001$ ). Further analysis revealed that there were significant differences in DA release among different elapsed time periods whatever dose of $\mathrm{MPH}$ was administered (except for MPH $0 \mathrm{mg} / \mathrm{kg}$ dose) (all $p<0.001)$ in the striatum. During the time periods of $1-2 \mathrm{~h}$ and $2-3 \mathrm{~h}$, there were significant differences in DA release depending on the MPH dose difference. Within each elapsed time period, statistically significant differences in DA release between different $\mathrm{MPH}$ doses are indicated in Figure $3 B$.

\section{Changes in DA release in the LPFC and striatum for the first $1 \mathrm{~h}$ sampling period}

There was a significant increase in DA release during the $15 \mathrm{~min}$ to $1 \mathrm{~h}$ time period compared with the basal level in the striatum, but not in the LPFC. To further examine the time period when $\mathrm{MPH}$ induced increases in DA release, we conducted another two-way ANOVA of DA release with the dose of $\mathrm{MPH}(0,1,2,5$, and $10 \mathrm{mg} / \mathrm{kg}$ ) and the elapsed time (15-30 $\mathrm{min}, 30-45 \mathrm{~min}$, and 45-60 min) after MPH administration as the main factors. 

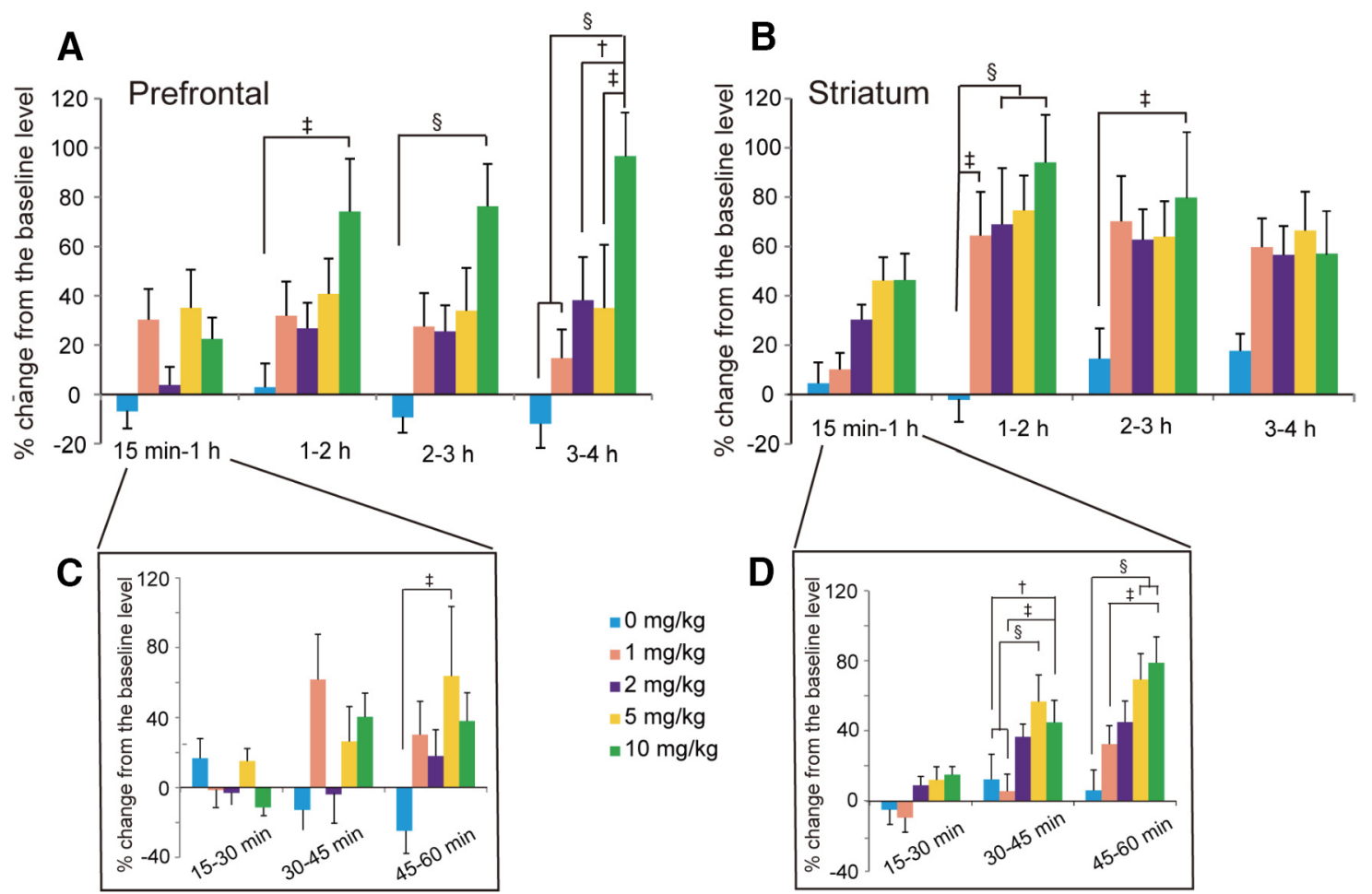

Figure 3. Time course of changes in DA release ( \pm SEM) for the $4 \mathrm{~h}$ after the administration of each dose $(1,2,5$, and $10 \mathrm{mg} / \mathrm{kg})$ of MPH in the PFC $(\boldsymbol{A})$ and striatum $(\boldsymbol{B})$. Inserts indicate the time course of changes in DA release ( \pm SEM) for the 60 min after the administration of each dose $(1,2,5$, and $10 \mathrm{mg} / \mathrm{kg}$ ) of MPH in the PFC (C) and striatum (D). The number of samples in the PFC was 6, 10, 12, 11, and 8 (Monkey M: right hemisphere, 2, 3, 4, 3, and 2, left hemisphere, 2, 2, 3, 3, and 2; Monkey J: right hemisphere, 1, 2, 2, 2, and 1, left hemisphere, 1, 3, 3, 3, and 3) and that in the striatum was 9, 11, 15, 14, and 15 (Monkey M: 3, 4, 7, 6, and 6; Monkey J: 6, 7, 8, 8, and 9), respectively, for 0, 1, 2, 5, and $10 \mathrm{mg} / \mathrm{kg}$ MPH administration. Statistically significant differences are indicated: $\nmid p<0.01, \neq p<0.005$, and $\$ p<0.001$.

Changes in DA release for each dose of $\mathrm{MPH}$ administration and for each elapsed time (15-30 $\mathrm{min}, 30-45 \mathrm{~min}$, and 45-60 min) after MPH administration are illustrated in Figure 3 for the LPFC (Fig. 3C) and striatum (Fig. 3D).

In the LPFC, there was no significant main effect in dose difference $\left(F_{(4,126)}=1.369, p=0.2610\right)$, but there was a significant main effect in elapsed time $\left(F_{(3,126)}=3.284, p=0.0231\right)$ and a significant interaction between the two factors $\left(F_{(12,126)}=1.890\right.$, $p=0.0414)$. Multiple comparisons using Ryan's method indicated that there were no significant differences in DA release between any pair of elapsed time periods. Further analysis revealed that, during the 30-45 min and 45-60 min periods, there were significant differences in DA release depending on the $\mathrm{MPH}$ dose difference $(p<0.05)$, although during the 30-45 min period, there was no significant difference in DA release between any pair of different $\mathrm{MPH}$ doses $(p>0.05)$ and, during the 45-60 min period, a significant increase in DA release was observed only with the dose of MPH $5 \mathrm{mg} / \mathrm{kg}$ compared with the dose of MPH $0 \mathrm{mg} / \mathrm{kg}$ (Fig. 3C). There was no clear increase in DA release within $1 \mathrm{~h}$ after the $10 \mathrm{mg} / \mathrm{kg} \mathrm{MPH}$ administration.

In the striatum, there were significant main effects for both factors of dose difference $\left(F_{(4,177)}=4.194, p=0.0047\right)$ and elapsed time $\left(F_{(3,177)}=26.954, p<0.001\right)$. There was also a significant interaction between the two factors $\left(F_{(12,177)}=3.218\right.$, $p=0.003)$. Multiple comparisons using Ryan's method indicated that the increases in DA release were significantly higher with the dose of MPH $10 \mathrm{mg} / \mathrm{kg}$ than with the dose of $1 \mathrm{mg} / \mathrm{kg}(p<0.005)$ and with the dose of $5 \mathrm{mg} / \mathrm{kg}$ than with the doses of $0 \mathrm{mg} / \mathrm{kg}(p<$ $0.01)$ and $1 \mathrm{mg} / \mathrm{kg}(p<0.005)$. In addition, there were significant differences in DA release between any pair of time periods $(p<$ 0.001 , except for between the time periods of $15-30 \mathrm{~min}$ and
$30-45 \mathrm{~min}$, where $p<0.05$ ) except for between the first $15 \mathrm{~min}$ period and the time period of 15-30 min. Further analysis indicated that during the $30-45 \mathrm{~min}$ and $45-60$ min periods, there were significant differences in DA increase depending on the MPH dose. Within each elapsed time period, statistically significant differences in DA release between different MPH doses are indicated in Figure 3D.

Therefore, in the LPFC, within $1 \mathrm{~h}$ after the oral administration of $\mathrm{MPH}$, no significant increase in DA release from the basal level was observed during the $30-45 \mathrm{~min}$ and $45-60$ min periods, although multiple comparisons indicated a significant increase in DA release with the MPH $5 \mathrm{mg} / \mathrm{kg}$ compared with the MPH 0 $\mathrm{mg} / \mathrm{kg}$ dose during the 45-60 min period (Fig. 3C). In the LPFC, there was no tendency of the higher dose of MPH to induce a larger increase in DA release. In the striatum, compared with the basal level, an increase in DA release was not observed during the 15-30 min period, but was observed during both the 30-45 min and 45-60 min time periods. Furthermore, during the 30-45 min and 45-60 min periods, significant differences in DA increase were observed depending on the MPH dose difference with a tendency for the higher dose of $\mathrm{MPH}$ to induce a larger increase in DA release (Fig. 3D).

\section{Results of delayed response task}

The results of the delayed response task are shown in Figure $4 \mathrm{~A}$. One-way ANOVA indicated a significant difference in the error rate depending on the MPH dose difference $\left(F_{(3,48)}=6.824, p=\right.$ 0.0006). Post hoc paired comparisons revealed that the error rate was significantly smaller with the doses of MPH 1,2, and $5 \mathrm{mg} / \mathrm{kg}$ than with the MPH $0 \mathrm{mg} / \mathrm{kg}$ dose, as shown in Figure $4 A$. 
A Delayed Response

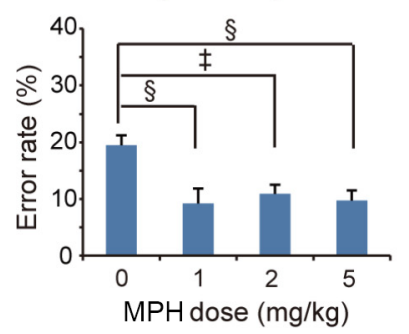

\section{B Go/No-go task}

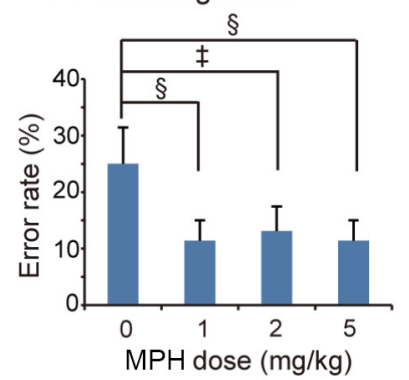

\section{No-go error}

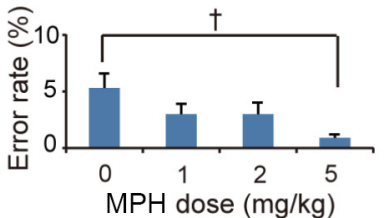

\section{Self control}

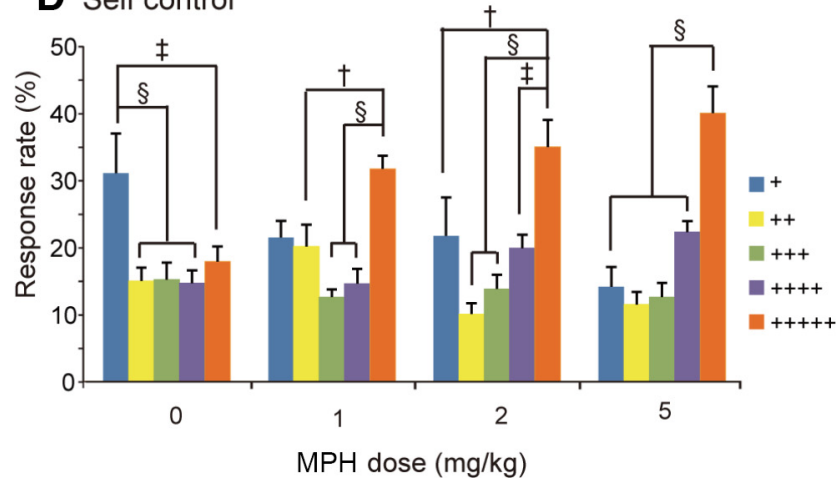

Figure 4. Dose-dependent effects of oral administration of MHP on cognitive task performance. $\boldsymbol{A}$, Error rates ( \pm SEM) for the delayed response task. $n=19,10,11$, and 12 (for Monkey $M$, it was 9, 5, 5, and 4 and, for Monkey J, it was 10, 5, 6, and 8), respectively, for the doses of 0 , 1, 2, and $5 \mathrm{mg} / \mathrm{kg} \mathrm{MPH.} \boldsymbol{B}$, Error rates ( \pm SEM) for the go/no-go task. C, No-go specific error rates ( \pm SEM) for the go/no-go task. For both $\boldsymbol{B}$ and $\boldsymbol{C}, n=15,10,9$, and 10 (for Monkey M, it was 8 , 5, 5, and 5 and, for Monkey J, it was 7, 5, 4, and 5), respectively, for the doses of 0, 1, 2, and 5 $\mathrm{mg} / \mathrm{kg}$ MPH. $\boldsymbol{D}$, Response rate ( \pm SEM) for each key in the self-control task. Each color indicates the number of plus marks within the target, the number of which indicated both the magnitude of the reward and the waiting time until reward delivery. $n=15,16,13$, and 11 (for Monkey $M$, it was 7, 8, 6, and 6 and, for Monkey J, it was 8, 8, 7, and 5), respectively, for the doses of 0, 1, 2, and $5 \mathrm{mg} / \mathrm{kg} \mathrm{MPH}$. Statistically significant differences are indicated: $\uparrow p<0.01, \neq p<0.005$, and $\S p<0.001$.

\section{Results of go/no-go task}

The results of the go/no-go task are shown in Figure 4B. One-way ANOVA indicated significant differences in the error rate depending on the MPH dose difference $\left(F_{(3,40)}=7.179\right.$, $p=0.0006)$. Post hoc paired comparisons revealed significantly smaller errors with the doses of MPH 1,2, and $5 \mathrm{mg} / \mathrm{kg}$ than with the MPH $0 \mathrm{mg} / \mathrm{kg}$ dose, as shown in Figure $4 B$. One-way ANOVA was also applied to no-go specific errors (where the monkey responded before the no-go waiting period of $1.5 \mathrm{~s}$ was over). There was a significant difference in the no-go error rate $\left(F_{(3,40)}=\right.$ $3.154, p=0.0352$ ), with a significant reduction in the no-go error rate with the MPH $5 \mathrm{mg} / \mathrm{kg}$ dose compared with the MPH 0 $\mathrm{mg} / \mathrm{kg}$ dose, as shown in Figure $4 C$.

\section{Results of self-control task}

The results of the self-control task are shown in Figure 4D. Twoway ANOVA for the data indicated a significant main effect of the number of plus marks (which indicate the reward magnitude as well as the delay time) in each $\operatorname{key}\left(F_{(4,204)}=18.120, p<0.001\right)$, but no significant main effect of MPH dose difference $\left(F_{(3,204)}=\right.$ $0.818, p=0.4901)$. The interaction of the two factors was significant $\left(F_{(12,204)}=3.744, p<0.0001\right)$. There were significant differences in the monkey's choice between the 5-plus key and all of the other keys, between the 3-plus key and the 1-plus key, and between the 2-plus key and the 1-plus key (all $p<001$ ). Further analysis indicated that there were significant differences in the monkey's choice depending on the number of plus marks on each key whatever dose of MPH was administered (Fig. 4D). For each MPH dose, statistically significant differences in the monkey's choice between different keys are indicated in Figure 4D.

\section{Discussion}

The present study confirmed previous human PET studies showing that MPH induced increases in DA release in the striatum. Low doses of MPH improved cognitive task performance, but a high dose of MPH made the monkey drowsy. Although previous microdialysis studies on rats indicated increases in DA release in the PFC with low doses of MPH (Berridge et al., 2006), we found a consistent increase in DA release in the PFC only with a high dose $(10 \mathrm{mg} / \mathrm{kg})$ of MPH $1 \mathrm{~h}$ after its administration. Therefore, our results in the monkey show a consistent increase in DA level in the striatum without consistent increase in DA level in the PFC by the low doses of MPH $(1,2$, or $5 \mathrm{mg} / \mathrm{kg})$, at least $1 \mathrm{~h}$ after their administrations. As far as we know, this is the first study to measure MPH-induced DA release from both places in the primate brain. Because the monkey brain is much more similar to the human brain than is the rodent brain, it is suggested that similar results would be obtained in the human.

\section{Differential influences of MHP administration in DA release between the LPFC and striatum}

In the LPFC, although a significant increase in DA release was observed during the 45-60 min period after the $5 \mathrm{mg} / \mathrm{kg}$, compared with $0 \mathrm{mg} / \mathrm{kg}, \mathrm{MPH}$ administration, there was no significant increase in DA release within $1 \mathrm{~h}$ after the other doses of MPH administration (Fig. 3C). Furthermore, $1 \mathrm{~h}$ after MPH administration, a significant increase in DA release was observed only with $10 \mathrm{mg} / \mathrm{kg} \mathrm{MPH}$, but not with 1,2 , and $5 \mathrm{mg} / \mathrm{kg} \mathrm{MPH}$. Therefore, as shown in Figure $3 A$, at least $1 \mathrm{~h}$ after the oral MPH administration, low doses of $\mathrm{MPH}(1,2$, or $5 \mathrm{mg} / \mathrm{kg})$ did not induce significant increases in DA release in the LPFC. In contrast, a clear increase in DA release in the striatum was observed whatever dose of MPH was administered during the $1-2 \mathrm{~h}$ postadministration period (Fig. $3 B$ ). The change in the striatum appeared to start by $30 \mathrm{~min}$, although the statistically significant change did not occur until the time period of 30-45 min after the MPH administration (Fig. 3D).

We conducted the LPFC experiments before the striatum experiments because there were possibilities of limb paralysis by inserting microdialysis probes in the striatum. Therefore, there is a possibility of sensitization phenomenon which may have induced a clear DA release in the striatum, but not in the LPFC, in our study. Furthermore, as indicated in Figure 3, there were 20$40 \%$ increases in DA release in the LPFC after low doses of MPH administration. Although these increases could not attain the significance level, except for $5 \mathrm{mg} / \mathrm{kg}$ MPH during the 30-45 min period, the increases in DA release with one or two low doses of 
MPH during the 30-45 min, 45-60 min, and 3-4 h periods were only slightly smaller than the statistically significant level. Considering that the significance threshold for each comparison in the post hoc pairwise comparison is very stringent, it could be said that the low doses of MPH induced almost marginally significant increases in DA release in the LPFC.

There are reports indicating that amphetamine, which is a catecholamine reuptake inhibitor that is effective in treating ADHD, increases DA levels in the PFC in monkeys (Jedema et al., 2014; Narendran et al., 2014). In these studies, the drug was administered intravenously and thus should have had much more direct and stronger effects on DA release in the brain. Because 10 $\mathrm{mg} / \mathrm{kg}$ MPH was effective at increasing the DA level in the LPFC in the present study, there is a possibility that an intravenously injected amphetamine had much stronger effects in increasing DA release in the LPFC than an orally administered MPH.

\section{Effects of oral administration of MPH on cognitive tasks}

As shown in Figure 4, we observed improvements in cognitive task performance with low doses of MPH administration. When $10 \mathrm{mg} / \mathrm{kg}$ MPH was administered, both monkeys became drowsy and performed the task only sporadically, so we could not obtain reliable data related to cognitive task performance with this $\mathrm{MPH}$ dose. During both the delayed response task and go/no-go task, the number of errors was reduced with the MPH doses of 1, 2, and $5 \mathrm{mg} / \mathrm{kg}$ administration. A significant decrease in the no-go specific error rate was also observed with the administration of 5 $\mathrm{mg} / \mathrm{kg} \mathrm{MPH}$, indicating that MPH facilitates the inhibitory function. During the self-control task, whereas monkeys preferred the 1-plus key (that indicated a small but immediate reward) to the other keys with $0 \mathrm{mg} / \mathrm{kg} \mathrm{MPH}$, they preferred the 5-plus key (that indicated the largest reward and longest waiting time) to other keys with $\mathrm{MPH}$ doses of 1,2 , and $5 \mathrm{mg} / \mathrm{kg}$ administration. Therefore, low doses of MPH appear to inhibit impulsive behavior in monkeys.

\section{Improvement in cognitive task performance by MPH administration}

The results of behavioral tests are consistent with previous studies showing improvement in a delayed response task (Gamo et al., 2010; Rajala et al., 2012) and a self-control task (Rajala et al., 2015) in the monkey.

However, according to Rajala et al. (2012), the significant improvement in WM task performance by MPH administration in their study came from the inhibition of premature responses, not from improved memory. Conversely, in a study by the same group (Rajala et al., 2015), MPH improved the discounting rate in the self-control task in the monkey. Therefore, MPH appears to affect attention and inhibition rather than WM.

There was a tendency for the task performance to improve with the dose of $5 \mathrm{mg} / \mathrm{kg}$, whereas the animal could not perform the task with the dose of $10 \mathrm{mg} / \mathrm{kg}$. Therefore, it appears that too much DA caused by $10 \mathrm{mg} / \mathrm{kg}$ MPH administration is detrimental for task performance, whereas the appropriate amount of DA may be around the value of MPH $1-5 \mathrm{mg} / \mathrm{kg}$.

\section{Striatum dopamine increase and LPFC activity}

The striatum itself is known to be involved in executive control such as planning and set shifting (Monchi et al., 2006b). Monchi et al. (2006a) indicated that during cognitive tasks that require PFC function, an increase in DA release is observed in the human striatum. Cognitive disabilities in Parkinson's disease (PD) patients are associated with DA depletion in the striatum (Grahn et al., 2008). It has been proposed that striatal DA depletion disrupts the normal pattern of striatal outflow in PD patients and consequently affects the expression of PFC functions by interrupting the normal transmission of information through PFC-striatal circuitry (Leh et al., 2010). Furthermore, in an fMRI study, an increase in DA in the striatum was shown to be associated with an activity increase in the PFC (Monchi et al., 2006a). Therefore, the increase in DA release caused by $\mathrm{MPH}$ in our study may have worked to facilitate cognitive task performance through an activity increase in the PFC-striatal network.

\section{Species difference in effects of MPH administration}

In the rat, MPH is reported to increase PFC DA by twofold or more at doses that are cognitively enhancing (Berridge et al., 2006), whereas in the human, a low dose of $\mathrm{MPH}$ is shown to increase the DA release in the striatum concomitant with improved cognitive task performance (Schabram et al., 2014). Importantly, in Berridge et al.'s (2006) study in rats, the MPHinduced DA increase in subcortical areas was smaller than that in the PFC. Our results in the monkey, which show a clear DA increase in the striatum, but an almost marginally significant increase in the PFC, stand in contrast to those obtained from rodents. Therefore, there appears to be clear species differences in the effects of oral administration of MPH on DA release in the brain between the rat and primate.

\section{Possible mechanisms of cognitive enhancement by MPH}

The symptoms of ADHD are known to be consistent with dysfunction of the PFC (Castellanos and Tannock, 2002) and LPFC DA plays an important role in cognitive operations (Cools and D'Esposito, 2011). However, our results indicate that low doses of oral administration of MPH induce a consistent increase in DA release in the striatum, but an almost marginally significant increase in the LPFC.

Therefore, it may be concluded that improvement of cognitive task performance caused by MPH administration may be mainly supported by the increased DA release in the striatum and/or by the PFC-striatum network-mediated neural activity increases in the PFC.

However, there is another possibility: that MPH works on cognitive operations through the PFC. An almost marginally significant increase in DA release may have facilitated PFC function. $\mathrm{MPH}$ is shown to induce changes in noradrenalin (NA) and PFC NA has also been shown to play an important role in cognitive operations (Arnsten and Li, 2005). Further studies are needed to investigate NA changes caused by $\mathrm{MPH}$ administration in the monkey PFC to determine whether the improvement of cognitive task performance by oral administration of MPH may also be mediated by changes in NA.

\section{References}

Arnsten AF, Li BM (2005) Neurobiology of executive functions: catecholamine influences on prefrontal cortical functions. Biol Psychiatry 57: 1377-1384. CrossRef Medline

Berridge CW, Devilbiss DM, Andrzejewski ME, Arnsten AF, Kelley AE, Schmeichel B, Hamilton C, Spencer RC (2006) Methylphenidate preferentially increases catecholamine neurotransmission within the prefrontal cortex at low doses that enhance cognitive function. Biol Psychiatry 60:1111-1120. CrossRef Medline

Biederman J, Faraone SV (2005) Attention-deficit hyperactivity disorder. Lancet 366:237-248. CrossRef Medline

Castellanos FX, Tannock R (2002) Neuroscience of attention-deficit/hyperactivity disorder: the search for endophenotypes. Nat Rev Neurosci 3:617-628. CrossRef Medline

Cools R, D’Esposito M (2011) Inverted-U-shaped dopamine actions on hu- 
man working memory and cognitive control. Biol Psychiatry 69:e113125. CrossRef Medline

del Campo N, Fryer TD, Hong YT, Smith R, Brichard L, Acosta-Cabronero J, Chamberlain SR, Tait R, Izquierdo D, Regenthal R, Dowson J, Suckling J, Baron JC, Aigbirhio FI, Robbins TW, Sahakian BJ, Müller U (2013) A positron emission tomography study of nigro-striatal dopaminergic mechanisms underlying attention: implications for ADHD and its treatment. Brain 136:3252-3270. CrossRef Medline

Gamo NJ, Wang M, Arnsten AF (2010) Methylphenidate and atomoxetine enhance prefrontal function through $\alpha 2$-adrenergic and dopamine D1 receptors. J Am Acad Child Adolesc Psychiatry 49:1011-1023. CrossRef Medline

Grahn JA, Parkinson JA, Owen AM (2008) The cognitive functions of the caudate nucleus. Prog Neurobiol 86:141-155. CrossRef Medline

Greenhill LL (2001) Clinical effects of stimulant medication in ADHD. In: Stimulant Drugs and ADHD: Basic and Clinical Neuroscience (Solanto MV, Arnsten AFT, Castellanos FX, eds), pp 31-71. New York: OUP.

Jedema HP, Narendran R, Bradberry CW (2014) Amphetamine-induced release of dopamine in primate prefrontal cortex and striatum: striking differences in magnitude and time course. J Neurochem 130:490-497. CrossRef Medline

Kodama T, Hikosaka K, Honda Y, Kojima T, Watanabe M (2014) Higher dopamine release induced by less rather than more preferred reward during a woking memory task in the primate prefrontal cortex. Behav Brain Res 266:104-107. CrossRef Medline

Leh SE, Petrides M, Strafella AP (2010) The neural circuitry of executive functions in healthy subjects and Parkinson's disease. Neuropsychopharmacology 35:70-85. CrossRef Medline

Linssen AM, Vuurman EF, Sambeth A, Riedel WJ (2012) Methylphenidate produces selective enhancement of declarative memory consolidation in healthy volunteers. Psychopharmacol (Berl) 221:611-619. CrossRef Medline

Mehta MA, Owen AM, Sahakian BJ, Mavaddat N, Pickard JD, Robbins TW (2000) Methylphenidate enhances working memory by modulating discrete frontal and parietal lobe regions in the human brain. J Neurosci 20:RC65. Medline

Monchi O, Ko JH, Strafella AP (2006a) Striatal dopamine release during performance of executive functions: A [(11)C] raclopride PET study. Neuroimage 33:907-912. CrossRef Medline

Monchi O, Petrides M, Strafella AP, Worsley KJ, Doyon J (2006b) Func- tional role of the basal ganglia in the planning and execution of actions. Ann Neurol 59:257-264. CrossRef Medline

Narendran R, Jedema HP, Lopresti BJ, Mason NS, Gurnsey K, Ruszkiewicz J, Chen CM, Deuitch L, Frankle WG, Bradberry CW (2014) Imaging dopamine transmission in the frontal cortex: a simultaneous microdialysis and [11C] FLB 457 PET study. Mol Psychiatry 19:302-310. CrossRef Medline

Rajala AZ, Henriques JB, Populin LC (2012) Disociative effects of methylphenidate in nonhuman primates: trade-offs between cognitive and behavioral performance. J Cogn Neurosci 24:1371-1381. CrossRef Medline

Rajala AZ, Jenison RL, Populin LC (2015) Decision making: effects of methylphenidate on temporal discounting in nonhuman primates. J Neurophysiol 114:70-79. CrossRef Medline

Robbins TW, Arnsten AF (2009) The neuropsychopharmacology of frontoexecutive function: monoaminergic modulation. Annu Rev Neurosci 32: 267-287. CrossRef Medline

Schabram I, Henkel K, Mohammadkhani Shali S, Dietrich C, Schmaljohann J, Winz O, Prinz S, Rademacher L, Neumaier B, Felzen M, Kumakura Y, Cumming P, Mottaghy FM, Gründer G, Vernaleken I (2014) Acute and sustained effects of methylphenidate on cognition and presynaptic dopamine metabolism: an [18F] FDOPA PET study. J Neurosci 34:14769_ 14776. CrossRef Medline

Spencer RC, Klein RM, Berridge CW (2012) Psychostimulants act within the prefrontal cortex to improve cognitive function. Biol Psychiatry 72: 221-227. CrossRef Medline

Spencer TJ (2002) Attention-deficit/hyperactivity disorder. Arch Neurol 59: 314-316. CrossRef Medline

Volkow ND, Wang G, Fowler JS, Logan J, Gerasimov M, Maynard L, Ding Y, Gatley SJ, Gifford A, Franceschi D (2001) Therapeutic doses of oral methylphenidate significantly increase extracellular dopamine in the human brain. J Neurosci 21:RC121. Medline

Volkow ND, Wang GJ, Fowler JS, Logan J, Franceschi D, Maynard L, Ding YS, Gatley SJ, Gifford A, Zhu W, Swanson JM (2002) Relationship between blockade of dopamine transporters by oral methylphenidate and the increases in extracellular dopamine: therapeutic implications. Synapse 43: 181-187. CrossRef Medline

Watanabe M, Kodama T, Hikosaka K (1997) Increase of extracellular dopamine in primate prefrontal cortex during a working memory task. J Neurophysiol 78:2795-2798. Medline 